\title{
High and Ultra-high Performance Concretes: A Solution to Reinforced Concrete Durability under Harsh Climate of Arabian Gulf
}

\author{
Muazzam Ghous Sohail \\ muazzam.ghous@qu.edu.qa \\ Center for Advanced Materials, Qatar University, Doha, Qatar \\ Ramazan Kahraman \\ ramazank@qu.edu.qa \\ Department of Chemical Engineering, Qatar University, Doha, Qatar \\ Nasser Al Nuaimi \\ anasser@qu.edu.qa \\ Center for Advanced Materials, Qatar University, Doha, Qatar \\ Wael Alnahhal \\ wael.alnahhal@qu.edu.qa \\ Department of Civil and Architectural Engineering, Qatar University, Doha, Qatar \\ Muhammad Wasee \\ wasee.ahmed@qu.edu.qa \\ Center for Advanced Materials, Qatar University, Doha, Qatar
}

\begin{abstract}
Reinforced concrete (RC) infrastructure in the Arabian Gulf region deteriorates under severe environmental conditions after only short service life. To overcome this problem, it is imperative to employ high-quality concretes and reinforce them with rebars that are corrosion resistant. This paper investigates the durability performance of newly developed high performance concretes (HPC) and ultra-high performance concretes (UHPC). The HPC and UHPC were manufactured using locally available materials in Qatar without employing any special treatment. The durability characteristics of HPC and UHPC in comparison to a normal strength concrete (NSC) were determined. Durability indicators such as concrete resistivity, sorptivity, porosity and resistance to chloride permeability were evaluated in order to access the durability of these concretes. These parameters were also compared to the concrete core samples taken from 30 to 50 years old RC structures in Doha city. The electrical resistivity of HPC and UHPC was 11 and 20 times higher than NSC, respectively. Sorptivity was 2 and 3 times less than NSC, respectively for HPC and UHPC. While the porosity of HPC and UHPC was 2.45 and $1.43 \%$ respectively. These newly fabricated concretes showed higher performance in durability testing than the concretes from real structures. With such attributes, the UHPC will be a useful tool in arresting the rapid deterioration of RC structures especially under harsh-climatic conditions of the Arabian Gulf.
\end{abstract}

Keywords: Durability of reinforced concrete infrastructure; High-performance concrete; Ultra-high-performance concrete; Durability indicators of RC structures

\section{INTRODUCTION}

The civil infrastructure including low and mid-rise residential construction, high rises, bridges, and harbors in Arabian Gulf and around the world are mostly reinforced concrete (RC). The RC structures in the Arabian Gulf are constantly subjected to extremely hot and humid environmental conditions (Al-Samarai, 2015). In global classification, the 
Gulf Region lies in an arid and subtropical climate with a total precipitation of $5 \mathrm{~cm} /$ year while the evaporation is $124 \mathrm{~cm} /$ year (Bazaraa, 1989). The temperature reaches $50{ }^{\circ} \mathrm{C}$ frequently in summer while the relative humidity $(\mathrm{RH})$ ranges between $60 \%$ to $100 \%$. In comparison with other seas, the Gulf water shows higher salinity with an average of $38.9 \mathrm{~g} /$ lit (Sohail et al., 2018a), while the groundwater chloride contents in Qatar range from $43 \mathrm{~g} / 1$ to $68 \mathrm{~g} / 1$ (Qatalum, 2006). The above mentioned environmental conditions cause RC structures to deteriorate well before their designed service lives (Sohail et al., 2019). Authors carried out a field study on 30 to 50 years old RC structures in the Arabian Gulf region in order to determine the environmental load and resistance factors. A serious deterioration was observed after 30 to 50 years of service life. It was observed that in most of the cases the chloride ion concentration was 4-6 times higher than the threshold to initiate the corrosion of mild steel reinforcing bars. The carbonation depth was up to $70 \mathrm{~mm}$ in some concretes. The average and maximum carbonation rates were calculated to be $6 \mathrm{~mm} / \sqrt{\text { year }}$ and $10.8 \mathrm{~mm} / \sqrt{\text { year }}$, respectively. The concrete resistivity to electrical charge, rapid chloride permeability, and sorptivity were measured (Sohail et al., 2018a). It was observed that, given the severe environment, the quality of concrete was not sufficient to fulfil the intended function over the design life. It was concluded that new construction materials and practices need to be adopted for future construction and repair to minimize the damage caused by these aggressive hot and humid conditions with high concentrations of chlorides both airborne and in groundwater.

High-performance concretes (HPC) and ultra-high performance concrete (UHPC) exhibit dense microstructure and low porosity, which make them suitable materials to arrest the degradation of RC structures subjected to harsh climatic conditions. HPC is defined as concrete with a compressive strength of up to $100 \mathrm{MPa}$ and workability equal to a self-compacting concrete (SCC). On another hand, the UHPC is defined as the concrete with a compressive strength above $150 \mathrm{MPa}$ and very high workability (Fehling et al., 2014a; Graybeal \& Tanesi, 2007; Sohail et al., 2018b). To be able to attain such high strength, flowability, and lower porosity, it is required to employ a water-to-cement (w/c) ratio between 0.2 to 0.3 , addition of pozzolanic supplementary cementitious materials (SCM), and high amount of superplasticizers are employed (Russel, G \& Graybeal, 2013; Wille et al., 2011a). Development of UHPC has been through several stages over time; first of kind was low-porosity-concrete (Yudenfreund et al., 1972) manufactured with finely ground cement and by applying external pressure on the paste to achieve lower porosity. Bache (1981) developed a concrete with higher compressive and flexural strength by adding micro-silica and a high amount of steel fibers, it was called a Densified concrete matrix (DCM). The matrix was very ductile with higher compression and flexural strengths. During the early manufacturing of UHPC, special treatments such as vacuum mixing, external pressure on fresh concrete, and heat curing are applied to achieve higher compressive strengths. However, these specific materials and special techniques were not practical for large scale applications. That is why the progress and use of UHPC was restricted. The latest form of UHPC was first developed by (Richard \& Cheyrezy, 1995), known as reactive powder concrete (RPC) with compressive strengths of $200 \mathrm{MPa}$ and $800 \mathrm{MPa}$. Ingredients were proportioned by employing a compressible packing model (CPM) presented by de Larrard and Sedran (1994). The homogeneity of RPC matrix was achieved by using micro-silica and heat curing at $95^{\circ} \mathrm{C}$. 
In this study, the high-performance and ultra-high-performance concrete were cast using locally available materials in Qatar. The mixture proportions were established to achieve $100 \mathrm{MPa}$. HPC and above $150 \mathrm{MPa}$ of UHPC. The durability indicators such as resistivity, sorptivity, porosity, and rapid chloride permeability were studied. These durability indicators were compared to normal concrete employed in the construction industry in recent times and to those concretes that were used to build RC structures in the 1970s, 1980s, and 1990s presented by Sohail et al. (2018a).

\section{EXPERIMENTAL DETAIL}

\subsection{Fabrication of HPC and UHPC; materials and mix proportion}

The manufacturing of UHPC was carried out by trial and error following the methods employed by (Wille et al., 2011b) and (Wong \& Kwan, 2008). Where the flow and strength are optimized by changing the quantities of cement, fine secondary cementitious materials, sand, water, and high range water reducers (HRWR). Flow cone tests in accordance with (ASTM C230/C230M14, 2014) were used to measure the flow of UHPC. The initial mixture proportion for trials was selected after performing an extensive literature review which has been published elsewhere (Sohail et al., 2018b), the mixture proportions that employs commonly available materials were selected to initiate the trials. A ratio of cement (C): silica fume (SF): fly ash (FA) of 1:0.25:0.25 was initially employed. All the materials are readily available in the construction market of Qatar. The trial mixtures were carried out by using 5L Pan Mixer. After several trials, the required strength and acceptable flow for UHPC were achieved, the finalized mixture proportions are shown in Table 1. In case of HPC the trial was also carried out by hit and trial, coarse aggregates of up to $10 \mathrm{~mm}$ were added in the mixture proportion. The mixture proportion for HPC and NSC are also presented in Table 1. The ordinary Portland cement (OPC) CEM I 42.5 R was used to cast all types of concretes; it was acquired from a local cement company. For NSC and HPC the gabbro aggregates with a maximum size of $10 \mathrm{~mm}$ and washed sand with 0/4.75 mm size were employed. For UHPC, two sand sizes were used, i) passing through $1180 \mu \mathrm{m}$ retained at $600 \mu \mathrm{m}$ and ii) passing through $600 \mu \mathrm{m}$ retained at $300 \mu \mathrm{m}$ sieves sizes, respectively. Finer than $300 \mu \mathrm{m}$ sand was removed to reduce the amount of fines in order to minimize the water demand. In case of HPC and UHPC, the addition of fly ash and silica fume is necessary. These two products are mostly imported to Qatar from India and China. The fly ash type F and Grey silica fume were used as secondary cementitious materials.

In the case of UHPC, the mixing procedure is as important as the ingredients selection. For UHPC, the ingredients were first dry mixed for 5 minutes in order to obtain a homogeneous mixture. Then half of the HRWR was added in one minute. The other half of HRWR was mixed with the water. This water containing HRWR was then poured into the mix slowly for 1 minute. The mixing was continued until a uniform flow able UHPC was obtained. The same procedure was adopted for trials mixes in 5 L PAN mixer and in 95 L PAN mixer to cast 65 liters of UHPC to prepare cylindrical $(100 \times 200 \mathrm{~mm})$ and prism $(100 \times 100 \times 350 \mathrm{~mm})$ samples. The NSC and HPC were mixed using Gravity Mixers.

The flow of NSC and HPC were measured according to (ASTM C1611 / C1611M 14, 2014) and for UHPC it was measured according to (ASTM C230/C230M14, 2014) 
without lifting and dropping the table. The total flow of the NSC for HPC in Abraham Cone was 535 and $586 \mathrm{~mm}$ and T50 was 7.8 and 6.8 seconds, respectively, in accordance with (ASTM C1611/C1611M-14, 2014). No vibration was applied during the casting of samples for durability testing. After 28 days, the maximum compressive strengths of NSC, HPC, and UHPC were $38 \mathrm{MPa}, 93 \mathrm{MPa}$, and $161 \mathrm{MPa}$, respectively.

Table 1: The mixture proportions of NSC, HPC, and UHPC

\begin{tabular}{|l|c|c|c|}
\hline Ingredients & $\mathbf{N S C}$ & $\mathbf{H P C}$ & $\mathbf{U H P C}$ \\
\hline & $\mathbf{K g} / \mathbf{m}^{\mathbf{3}}$ & $\mathbf{K g} / \mathbf{m}^{\mathbf{3}}$ & $\mathbf{K g} / \mathbf{m}^{\mathbf{3}}$ \\
\hline Cement & 410 & 640 & 820 \\
\hline Silica Fume & - & 128 & 190 \\
\hline Fly Ash & - & 128 & 148 \\
\hline Sand $(0 / 4 \mathrm{~mm})$ & 962 & 700 & - \\
\hline Fine sand 1(retained at $600 \mu \mathrm{m})$ & - & - & 718 \\
\hline Fine sand 2 (retained at $300 \mu \mathrm{m})$ & - & - & 308 \\
\hline Coarse $(0 / 10 \mathrm{~mm})$ & 965 & 550 & - \\
\hline Water & 159 & 200 & 172 \\
\hline SP & 5.2 & 10 & 25 \\
\hline Flow $(\mathrm{mm})$ & $535^{\sim}$ & 586 & $280 *$ \\
\hline $\mathrm{T}_{50}($ sec $)$ & 7.8 & 6 & $\mathrm{NA}$ \\
\hline 7 days compressive strength $(\mathrm{MPa})$ & 23.5 & 54 & 86 \\
\hline 28 days compressive strength $(\mathrm{MPa})$ & $\mathbf{3 7 . 5}$ & $\mathbf{9 3}$ & $\mathbf{1 6 1}$ \\
\hline 90 days compressive strength $(\mathrm{MPa})$ & 48 & 105 & $\mathbf{1 6 3}$ \\
\hline$\sim$ ASTM C1611-14, *ASTM C230/C230M & & & \\
\hline
\end{tabular}

The failure mode of NSC, HPC, and UHPC is distinctly different in compression test. The NSC cylinders failed in cement matrix with failure lines passing throughout the lengths. While in case of HPC and UHPC, the failure was abrupt with a blast of cylindrical samples. The failure in HPC was through the aggregates and matrix, the failure shape was conical in both HPC and UHPC.

\section{Durability Testing}

\subsubsection{Concrete resistivity}

Concrete's electrical resistivity is an indicator of its quality, a high-quality concrete shows very high electrical resistance, while porous and low-quality concrete shows easy flow of electrical currents. Lower the value of concrete resistivity, higher is the risk of corrosion. Concrete resistivity higher than 20,000 Ohm.cm would present negligible corrosion risk to the reinforcing steel rebars. Concrete resistivity was measured on three cylindrical concrete samples of 100x200 $\mathrm{mm}$ at 28 days of curing in accordance with (AASHTO TP 95, 2011). The samples were kept in saturated stat to eliminate the humidity effects on the resistivity values. 


\subsubsection{Rapid Chloride Permeability Test (RCPT)}

Rapid chloride penetrability was measured on $100 \times 50 \mathrm{~mm}$ in accordance with (ASTM C1202-12, 2012). These disk samples were taken from 100x200 cylinders after testing for resistivity. The disk samples were kept in oven at $50^{\circ} \mathrm{C}$ for three days, then immersed underwater and a vacuum of $50 \mathrm{~mm} \mathrm{Hg}$ was applied for 18 hours. After this conditioning, the samples were placed between two chambers with $3.5 \% \mathrm{NaCl}^{-}$in one and $0.3 \mathrm{NaOH}$ in the other. A voltage of $60 \mathrm{~V}$ was applied on two terminals and current passing through the concrete samples was measured. Total charge transfer was measured over a period of 6 hours.

\subsubsection{Sorptivity}

Sorptivity is a very relevant indicator of long-term durability of concrete. It measures the amount of moisture that could be transported and contained into an unsaturated concrete (Dias, 2013; Patel, 2009). ASTM C1585-13 (2013) was followed to measure the sorptivity of concrete core samples $(100 \times 50 \mathrm{~mm})$. The samples were placed in an environmental chamber with $50^{\circ} \mathrm{C}$ and $\mathrm{RH}$ of $80 \%$ for 3 days, and then kept in a laboratory environment for 15 days before being used for sorptivity tests. The samples were immersed into distilled water and the change in weight was measured at time intervals mentioned in (ASTM C1585-13, 2013).

\subsubsection{Porosity}

The porosity of NSC, HPC, and UHPC was measured according to ASTM C1754/ C1754M-12. Cylindrical concrete samples of $100 \mathrm{~mm}$ x $200 \mathrm{~mm}$ were cut to a height of $50 \mathrm{~mm}$ size. Samples were dried at $38^{\circ} \mathrm{C}$ and weight was measured after 24 hours. The samples were kept in the oven until the weight became constant or change is about $0.5 \%$. Then samples were completely submerged into the water for 30 minutes and submerged weight was recorded. Total void contents were calculated by the formulas provided by ASTM C1754/C1754M-12.

\section{RESULTS AND DISCUSSION}

\subsection{Resistivity}

Average concrete resistivity values from three old $\mathrm{RC}$ structures and of newly fabricated NSC, HPC and UHPC are shown in Figure 1. The RC structures had resistivity less than $10000 \mathrm{Ohm}-\mathrm{cm}$, a higher risk of steel corrosion is associated with such lower resistivity values. The NSC, HPC, and UHPC after 28 days of curing had a resistivity of 25041, 336006, and $457483 \mathrm{Ohm}-\mathrm{cm}$ respectively. These are considered very high resistivities and indicate no-corrosion risk present in RC. The HPC and UHPC have 6 to 10 time's higher resistance to electric current than conventional concretes. In addition, about 45 times higher resistivity than the practiced concrete until 1990s in the Middle Eastern region. With such high resistance, the ingress of chlorides and carbon dioxide will be minimized and the corrosion process will be hindered. 


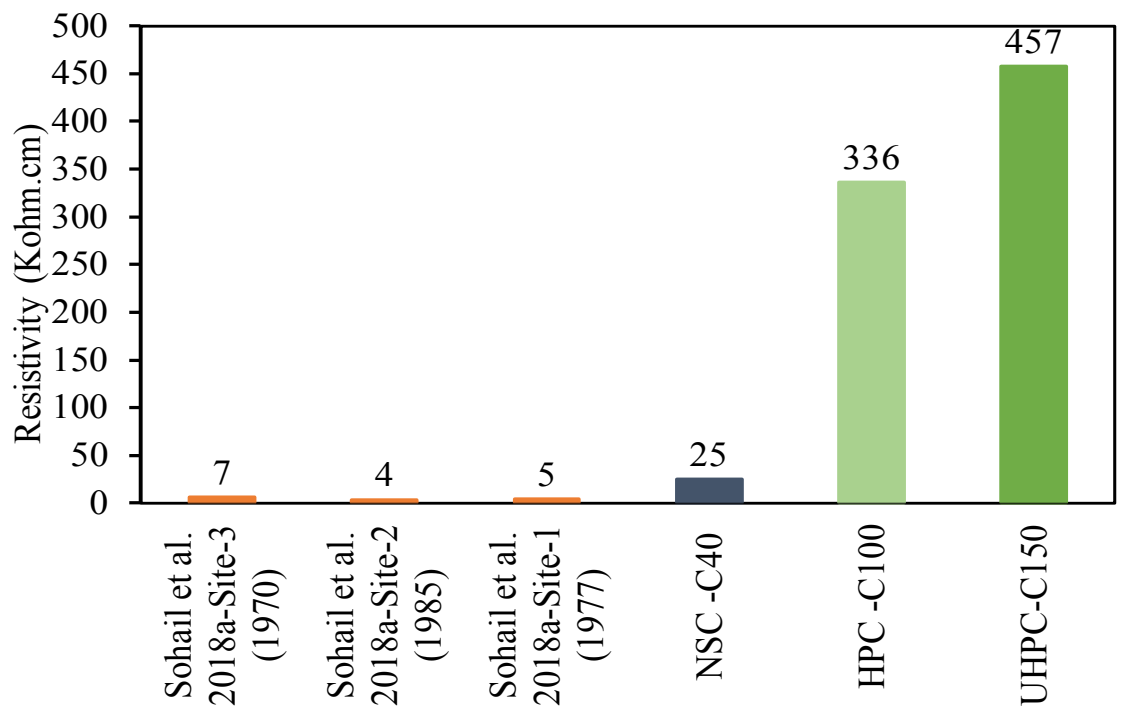

Figure 1: Concrete resistivity from columns of old reinforced concrete structures against the resistivity from cylinders of NSC at 90 days, HPC at 90 days and UHPC at 60 days

\subsection{Sorptivity}

A comparison between initial sorptivity of old concretes (the values of which are presented by (Sohail et al., 2018a) and newly fabricated NSC, HPC, and UHPC are shown in Figure 2a. The average initial sorptivity values for columns of three studied structures were up to $680 \times 10^{-4} \mathrm{~mm} / \mathrm{s}^{1 / 2}$. While for NSC it was $43 \times 10^{-4} \mathrm{~mm} / \mathrm{s}^{1 / 2}$, for HPC and UHPC it was found to be $25 \times 10^{-4} \mathrm{~mm} / \mathrm{s}^{1 / 2}$ and $11 \times 10^{-4} \mathrm{~mm} / \mathrm{s}^{1 / 2}$, respectively. The sorptivity for HPC and UHPC is significantly lower. Such lower sorptivity will considerably reduce the ingress of deleterious materials like $\mathrm{Cl}^{-}$or carbonation in concrete and hence will improve the durability for longer periods. Lower initial sorptivity indicates the dense microstructure and disconnected capillary pores in case of HPC and UHPC.

\subsection{RCPT values}

The average RCPT values were observed to be 5148, 120 and 45 Coulombs for NSC, HPC, and UHPC, respectively (Figure 2b), while these values were up to 1000 Coulombs in concrete from RC structures built from the 1970s, 1980s, and 1990s. The sorptivity and RCPT for NSC are relatively higher, this could be due to no vibration applied and might have interconnected pores. The HPC and UHPC are expected to increase the durability of RC structures with such lower RCPT values.

\subsection{Porosity}

The porosity of NSC, HPC and UHPC were respectively 5.5, 2.4 and 1.43\%. Such lower porosity will restrict the amount of water to be absorbed into the concrete volume. 

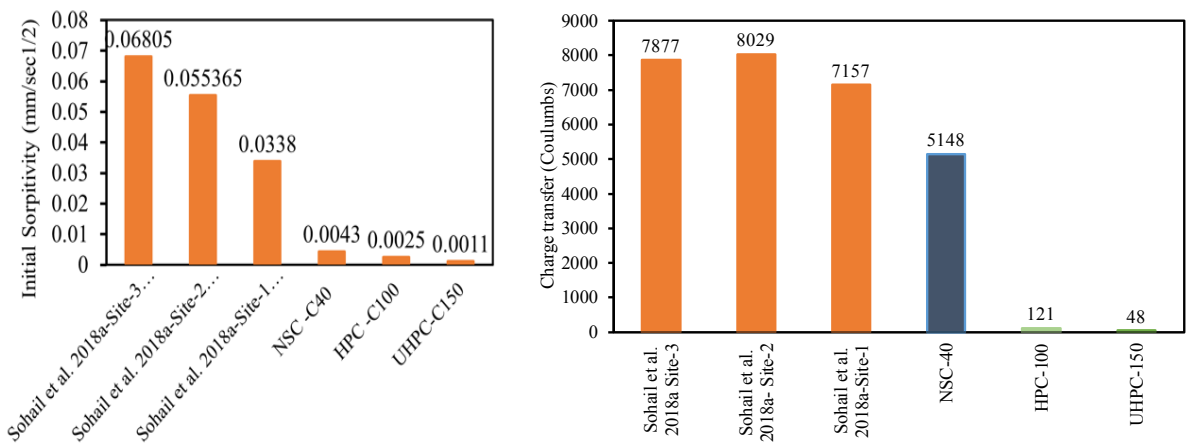

a)

b)

Figure 2: a) Sorptivity values, b) RCPT values of NSC, HPC and UHPC in comparison to values from old concrete

\section{CONCLUSION}

High and ultra-high performance concretes were cast using locally available materials in the Qatari construction market. These concretes are expected to arrest the deterioration of reinforced concrete (RC) infrastructure under the action of severe environmental conditions. The durability indicators are compared against normal strength concrete and to those concretes that were used to build RC structures in 1970, 1980, and 1990s. The following are some major conclusions:

- The concrete resistivity of HPC and UHPC was 11 and 20 times higher than normal strength concrete. This shows a dense microstructure of HPC and UHPC. Ingress of deleterious agents will take a longer time to reach the steel-concrete interface, hence delayed corrosion initiation. Also once the corrosion is initiated the movement of $\mathrm{Fe} 2+$ and $\mathrm{OH}$ - ions will be hindered and the corrosion process will be retarded.

- HPC and UHPC shoed negligible passage of charge transfer in RCPT, which indicated the less pore volume and their disconnectivity.

- HPC and UHPC showed a porosity of 2.4 and $1.43 \%$ respectively. With such lower porosity, the ability to absorb water is reduced. Hence no ingress of deleterious agents.

- The sorptivity of these newly developed concretes is also very low, in comparison to normal strength concrete, HPC and UHPC showed 2 and 3 times lower values, respectively. While compared to core samples from old RC structures, these values were up to 60 times lower.

With such attributions, the HPC and UHPC could a very useful tool to overcome the durability issues, especially in the region of the Arabian Gulf, where very harsh climatic conditions are encountered.

\section{ACKNOWLEDGMENTS}

The funding for this research was provided by the National Priorities Research Program of the Qatar National Research Fund (a member of the Qatar Foundation) 
under the award no. NPRP 7-410-2-169. The statements made herein are solely the responsibility of the authors and do not necessarily reflect the opinions of the Sponsor.

\section{REFERENCES}

AASHTO TP 95 (2011). Standard Method of Test for Surface Resistivity Indication of Concrete's Ability to Resist Chloride Ion Penetration. American Association of State Highway and Transportation Officials, Washington, D.C.

Al-Samarai, M. (2015). Durability of Concrete in the Arabian Gulf. Journal of Materials Science and Engineering A, 5, 11-12.

ASTM C1202-12. (2012). Standard Test Method for Electrical Indication of Concrete's Ability to Resist Chloride Ion Penetration. ASTM International, West Conshohocken, PA, 2012.

ASTM C1585-13. (2013). ASTM C1585-13 Standard Test Method for Measurement of Rate of Absorption of Water by Hydraulic-Cement Concretes.

ASTM C1611/C1611M-14. (2014). Standard Test Method for Slump Flow of Self-Consolidating Concrete. West Conshohocken, PA.

ASTM C1754/C1754M-12. (2012). Standard Test Method for Density and Void Content of Hardened Pervious Concrete.

ASTM C230/C230M14. (2014). Standard Specification for Flow Table for Use in Tests of Hydraulic Cement. ASTM International, West Conshohocken, PA.

Bache, H. (1981). Densified cement/ ultra fine particle based materials. The second International conference on superplasticizers in Concrete, Ottawa, Ontario, Canada June 10-12, 1981.

Bazaraa, A. S. (1989). Estimates of potential evapotranspiration over The State of Qatar. Qatar University, 2.

Dias, W. P. S. (2013). Reduction of concrete sorptivity with age through carbonation.

Fehling, E., Michael, S., Joost, W. \& et al. (2014). Ultra-High Performance Concrete UHPC: Fundamentals, Design, Examples.

Graybeal, B. A. \& Russell, H. G. (2013). Ultra-High Performance Concrete: A State-Of-The-Art Report for The Bridge Community (FHWA-HRT-13-060).

$<$ https://www.fhwa.dot.gov/publications/research/infrastructure/structures/hpc/13060/> (Nov. 9, 2015).

Graybeal, B. \& Tanesi, J. (2007). Durability of an Ultrahigh-Performance Concrete. Journal of Materials in Civil Engineering, 19(10), 848-854.

de Larrard, F. \& Sedran, T. (1994). Optimization of ultra-high-performance concrete by the use of a packing model. Cement and Concrete Research, 24(6), 997-1009.

Patel, V. N. (2009). Sorptivity testing to assess durability of concrete against freeze-thaw cycling. The Department of Civil Engineering and Applied Mechanics McGill University Montreal, Canada.

Qatalum. (2006). Environmental Impact Assessment. Doha.

Richard, P. \& Cheyrezy, M. (1995). Composition of reactive powder concretes. Cement and Concrete Research, 25(7), 1501-1511.

Sohail, M. G., Kahraman, R., Ozerkan, N. G., Alnuaimi, N. A., Gencturk, B., Dawood, M. \& 
Belarbi, A. (2018a). Reinforced Concrete Degradation in the Harsh Climates of the Arabian Gulf: Field Study on 30-to-50-Year-Old Structures. Journal of Performance of Constructed Facilities, 32(5), 04018059 (1-12).

Sohail, M. G., Salih, M., Al Nuaimi, N. \& Kahraman, R. (2019). Corrosion performance of mild steel and epoxy coated rebar in concrete under simulated harsh environment. International Journal of Building Pathology and Adaptation, Emerald Group Publishing Ltd., 37(5), 657678.

Sohail, M. G., Wang, B., Jain, A., Kahraman, R., Ozerkan, N. G., Gencturk, B., Dawood, M. \& Belarbi, A. (2018b). Advancements in Concrete Mix Designs: High-Performance and Ultrahigh-Performance Concretes from 1970 to 2016. Journal of Materials in Civil Engineering, 30(3), 04017310.

Wille, K., Naaman, A. E. \& El-Tawil, S. (2011a). Optimizing Ultra-High Performance FiberReinforced Concrete. Concrete International, 33(9), 35-41.

Wille, K., Naaman, A. E., El-Tawil, S. \& Parra-Montesinos, G. J. (2012). Ultra-high performance concrete and fiber reinforced concrete: achieving strength and ductility without heat curing. Materials and Structures, Springer Netherlands, 45(3), 309-324.

Wille, K., Naaman, A. E. \& Parra-Montesinos, G. J. (2011b). Ultra-High Performance Concrete with Compressive Strength Exceeding $150 \mathrm{MPa}$ (22 ksi): A Simpler Way. Materials Journal, 108(1), 46-54.

Wong, H. H. C. \& Kwan, A. K. H. (2008). Packing density of cementitious materials: part 1measurement using a wet packing method. Materials and Structures, Springer Netherlands, 41(4), 689-701.

Yudenfreund, M., Skalny, J., Mikhail, R. S. \& Brunauer, S. (1972). Hardened portland cement pastes of low porosity II. Exploratory studies. Dimensional changes. Cement and Concrete Research, 2(3), 331-348.

Cite this article as: Sohail M. G., Kahraman R., Al Nuaimi N., Alnahhal W., Wasee M., "High and 